\title{
Laser measurement of building vibration and displacement ${ }^{1}$
}

\author{
A.J. Bougard and B.R. Ellis \\ Centre for Structural Engineering, Building Research \\ Establishment, Bucknalls Lane, Garston, Watford, \\ Hertfordshire WD2 7JR, UK
}

Received 16 June 2000

Revised 16 June 2000

This paper considers four laser systems used by the Building Research Establishment (BRE) to investigate the behaviour of structures. Lasers enable remote measurements of vibration and displacement to be taken where access to a structure is difficult or where fire, explosion or structural collapse creates a hazardous environment. Each system will be described, and its use illustrated using measurements taken on real structures.

The four systems are:

1. Laser Interferometer: This is used to measure the velocity of vibration of a structure under ambient loading.

2. 3D-Laser Survey System: This is used to track the movement of any number of targets on a structure under load.

3. VHS Laser System: This is used to measure displacement of a target moving at high velocities.

4. Tracking Lasers: This is used to track the angular displacements of a target.

Keywords: Displacement, dynamics, lasers, structures, vibration

\section{Introduction}

The development of instruments based on lasers has led to many useful and often very accurate systems which can be used in civil and structural engineering.

\footnotetext{
${ }^{1}$ An earlier form of this paper was presented at the 3rd International Conference on Vibration Measurements by Laser Techniques, Ancona, Italy, June 1998. The conference was organized by the Italian Association of Laser Velocimetry. The articles were selected, edited, and reviewed by a committee chaired by: Professor Enrico Primo Tomasini, Department of Mechanics, Faculty of Engineering, University of Ancona, Italy.
}

Construction lasers first appeared in 1967 when laser beams were used for aligning pipe runs [1]. Lasers have since been developed for use in a range of surveying techniques and are now widely available. Lasers can also be used for the measurement of movement of structures and they offer many advantages over conventional measurement systems.

The Centre for Structural Engineering at the Building Research Establishment (BRE) is often involved with investigations of the structural behaviour of buildings. This includes determining the dynamic characteristics of structures and evaluating structural response to various dynamic loads. Most of the experimental work is undertaken on full-scale structures including vibration measurements of tall buildings, floors and grandstands. Structural response to explosions and fire is also an important subject but physical tests create a hazardous environment for traditional instrumentation. In recent years, the BRE has used a number of laser systems to take remote measurements of vibration and displacement where access to a structure is difficult or dangerous. By enabling more measurements to be taken on real buildings, lasers are playing a significant role in increasing our knowledge of structural behaviour.

\section{Laser interferometer}

BRE uses a long range laser interferometer for measuring sub-micron vibration of structures, at distances up to $150 \mathrm{~m}$ from concrete surfaces and more than $500 \mathrm{~m}$ from prepared reflective surfaces. Measurements can be made on targets with peak velocities up to $8 \mathrm{~mm} / \mathrm{sec}$ at frequencies from $0.1 \mathrm{~Hz}$ to $1 \mathrm{kHz}$. Speckle tracking enables good signals to be obtained without dropouts in optically turbulent atmospheres. The system is developed for measuring vibrations in line with the laser beam, although information on movements in the orthogonal plane can be obtained from the tracking system. The main output is an analogue voltage which is proportional to velocity, together with an output of the signal after integration which is proportional to dis- 


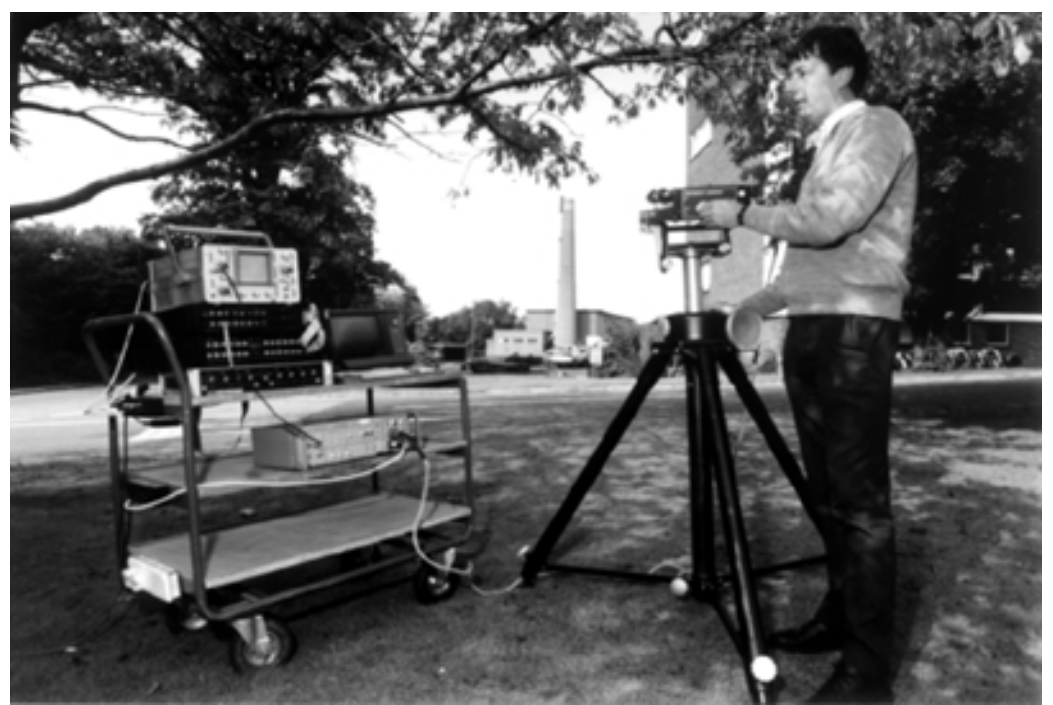

Fig. 1. Laser interferometer in operation.

placement. Figure 1 shows the laser interferometer being operated by one of the authors.

The laser interferometer has been used to determine the natural frequencies of three full-scale test buildings built inside a huge former airship hangar at BRE's Cardington site. These include an eight-storey high steel framed building [2], a six-storey timber framed building and a seven-storey in-situ concrete building. The timber framed construction will be used as an illustration and this building represents a six-storey block of flats with a total height of $19 \mathrm{~m}$, covering a plan area of $23.5 \mathrm{~m} \times 12 \mathrm{~m}$. As each new storey was added to the building, the laser interferometer was used to measure the natural vibration of the building caused by air movement in the hangar.

The laser system was set up approximately $20 \mathrm{~m}$ from the south face to measure vibration in the northsouth (NS) direction, and $40 \mathrm{~m}$ from the east face for measurements in the east-west (EW) direction. The basic measuring procedure involved directing the laser on to the face of the building and focusing the beam to give a strong output signal for analysis. The output voltage was then fed into signal conditioning equipment and recorded on a computer for 409.6 seconds at a sampling rate of $20 \mathrm{~Hz}$ to give a total of 8192 (8k) datapoints.

A fast Fourier transform (FFT) was then used to convert the velocity-time history into an autospectrum, to determine the frequency content of the signal. Figure 2 is an autospectrum showing the building frequencies determined from the velocity-time history recorded at the top north corner of the east face of the building. In order to identify particular modes, measurements were taken at five positions on both the east and south faces during the latter part of the construction. Measurements at the top centre of the building tend to eliminate the torsion and orthogonal direction translation modes, whilst measurements at two-thirds of the building's height tend to eliminate the second order modes. At the corners of the building, the response in the torsion mode can be identified.

In Fig. 2, which is taken from movement in the eastwest direction, the fundamental frequency is clearly seen at $2.52 \mathrm{~Hz}$. The fundamental torsional frequency can also identified at $3.22 \mathrm{~Hz}$. The second order eastwest mode frequency is approximately $6.14 \mathrm{~Hz}$, whilst movement was also detected at $1.93 \mathrm{~Hz}$, which is the fundamental frequency in the orthogonal north-south direction.

The natural frequencies were identified at various stages of construction to see how the dynamic characteristics of the building change with increase in height and with the addition of roof tiles, brick cladding and plasterboard. The laser measured frequencies can also be compared to theoretical natural frequencies calculated from a finite element computer model of the building. This comparison enables the computer model to be calibrated thereby providing a more accurate model of the behaviour of the real-life structure.

Although the laser interferometer can be used to determine natural frequencies, it can not be used to determine other important dynamic characteristics such as damping, stiffness and mode shape. This requires a known force to be applied to the structure by attaching 


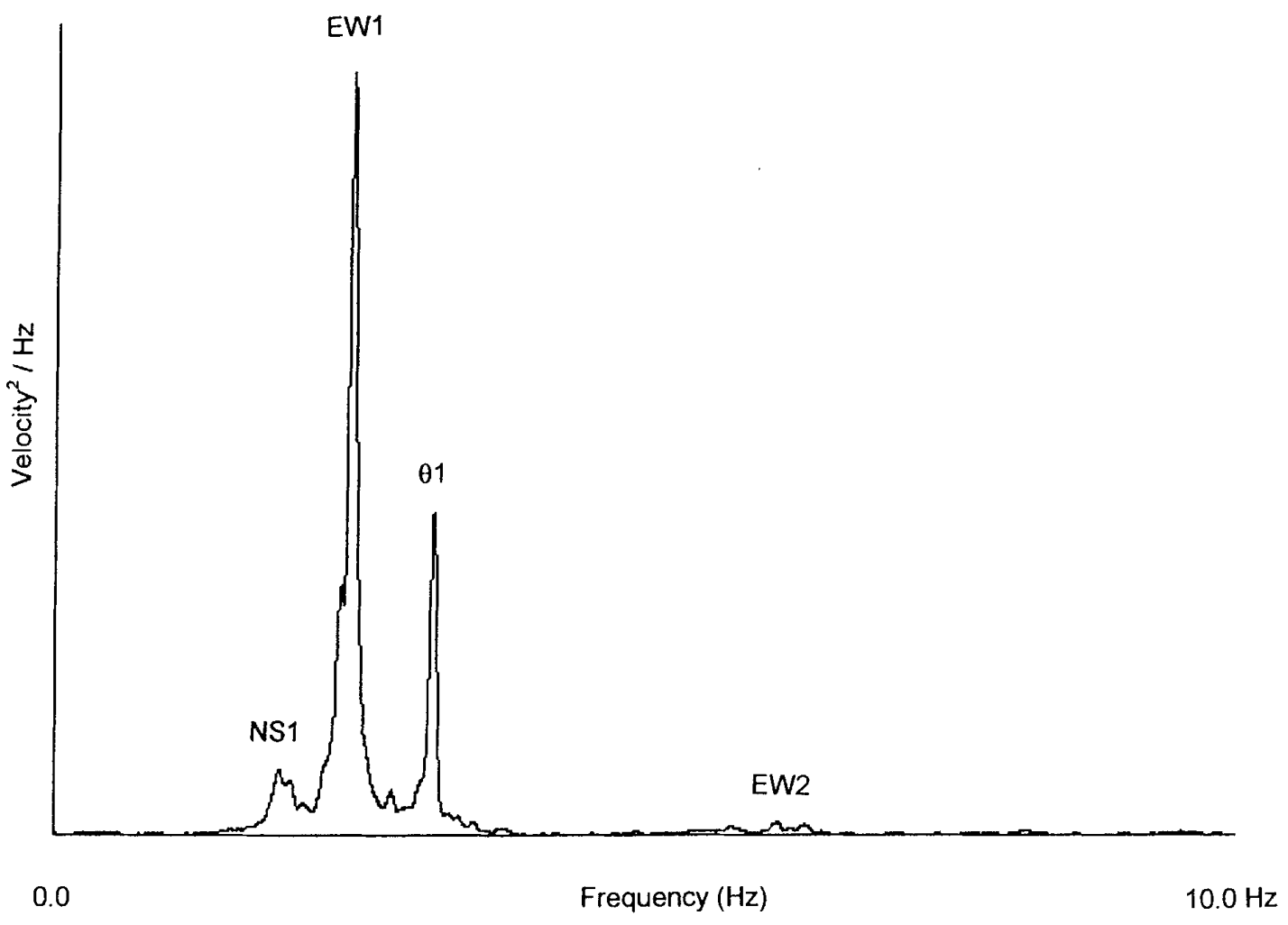

Fig. 2. An autospectrum measured for the Timber Frame 2000.

heavy equipment to the building. Although forced vibration testing provides important information, it can be time consuming, whilst the laser has the advantage that measurements of natural frequency can be taken remotely and quickly, with no disruption to construction work or to a building's occupants.

As natural frequency is related to stiffness, the laser interferometer was used to determine whether damage to a structure could be identified through frequency measurements. This was investigated by measuring the natural frequencies of the eight-storey, steel framed building before and after fire and explosion damage was inflicted on the building. Although the building sustained significant local damage such as buckled beams and cracked concrete floors, the main bracing elements of the building were left untouched. As a result, the laser interferometer measurements confirmed that the stiffness of the whole building was not significantly affected by this large amount of damage.

Although the detection of local damage to buildings is difficult, primarily due to the large degree of redundancy in most buildings, the laser interferometer has been used to detect damage in much smaller and simpler structural elements. In particular, the stone pin- nacles which decorate many cathedrals and important historic structures around Europe, have been found to be relatively simple structures with easily identifiable modes. Over 500 of these stone pinnacles adorn the turrets and spires of the Houses of Parliament in the Palace of Westminster in London [3]. Several pinnacles have fallen off following gradual weathering from years of exposure to the elements, but detection of these defects by a traditional structural survey would be difficult and expensive.

Figure 3 is a photograph of the clock tower which houses Big Ben, in which two of the four $3.6 \mathrm{~m}$ stone pinnacles can be seen silhouetted against the sky at opposite corners of the tower just above the clock face. The laser interferometer was set up at ground level and the laser beam aimed at one of the pinnacles over $100 \mathrm{~m}$ away. An autospectrum from an $82 \mathrm{~s}$ recording of one of these pinnacles is shown in Fig. 4. Here the lower frequencies are those of the tower whilst the pinnacle frequency is somewhat higher at $14.95 \mathrm{~Hz}$. A repeated measurement on a position on the tower away from the pinnacle provides the same tower frequencies but the pinnacle mode is absent. Frequency measurements for all four pinnacles should be similar if the pinnacles are 


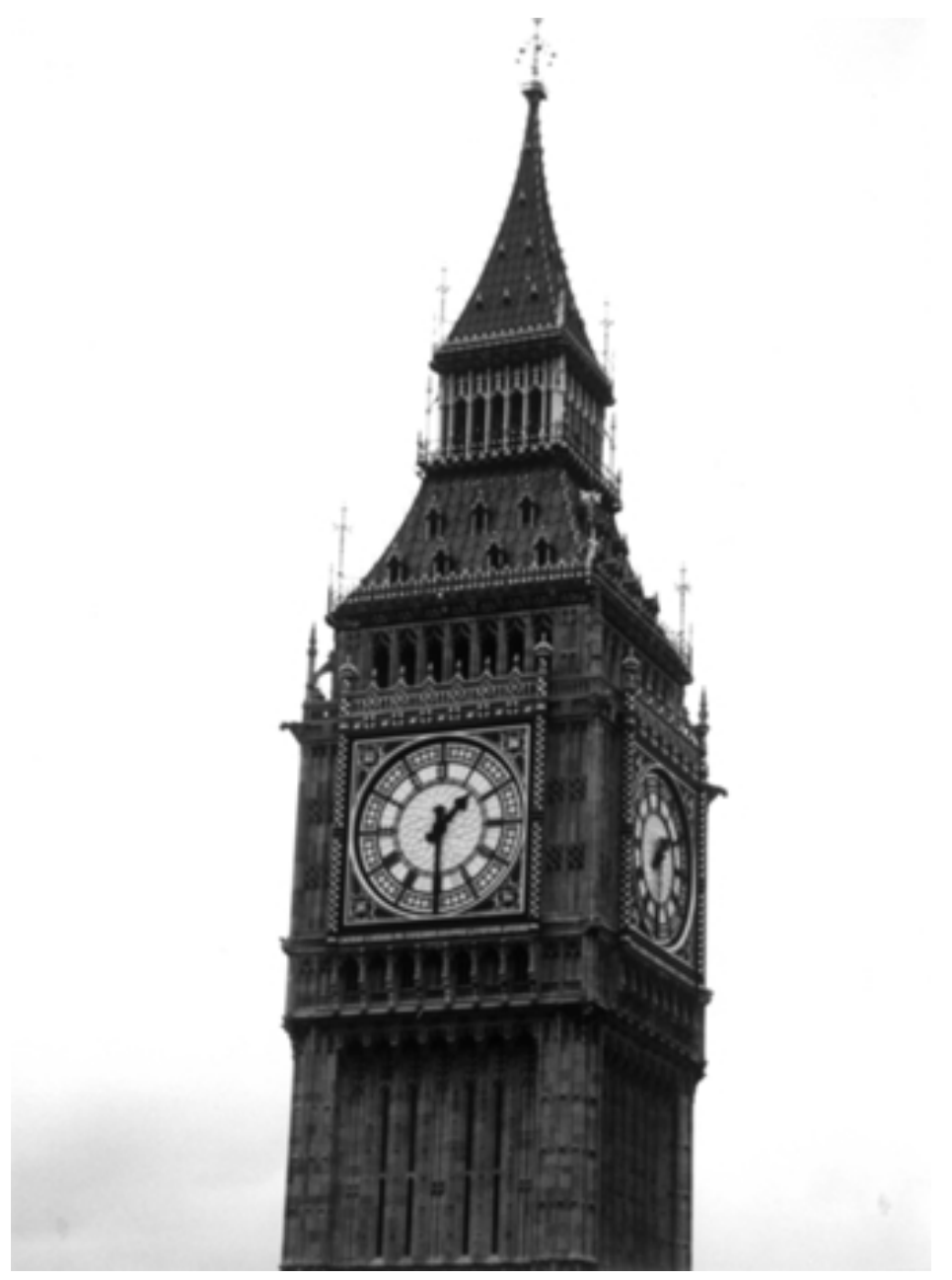

Fig. 3. Clock tower at the Palace of Westminster.

identical in mass and stiffness. Therefore the tests procedure was to measure the fundamental frequencies of all the pinnacles on the Palace and compare the values obtained on identical pinnacles. Any pinnacle which was significantly different to the norm was therefore identified, with the implication that a damaged pinnacle will have a reduced stiffness and frequency.

The technique developed at the Houses of Parliament can equally be used for assessing damage to parts of modern buildings. For instance, the facade of many office buildings are made up of stone or concrete cladding panels, most of which are mass produced to the same size and weight for a particular office building. Damage can be caused to the cladding panels by corrosion, wind, rain or more dramatically by bomb explosions. For investigative purposes, the laser interferometer was taken into the City of London to assess damage to cladding panels on a building, following one of the large explosions there in recent years. The laser was set up on the roof of a building opposite, and natural frequencies determined for each of the cladding panels. Damaged panels could be readily identified because of their different properties.

The laser interferometer has proved to be an invaluable tool for investigating the dynamic behaviour of structures because of the speed and ease with which frequency measurements can be taken on buildings without disturbance to the building's occupants or the need to access the measurement position directly.

\section{3D-Laser Survey System}

The 3D-Laser Survey System (3D-LSS) was developed for remotely measuring small deformations of large structures. The system will measure displace- 


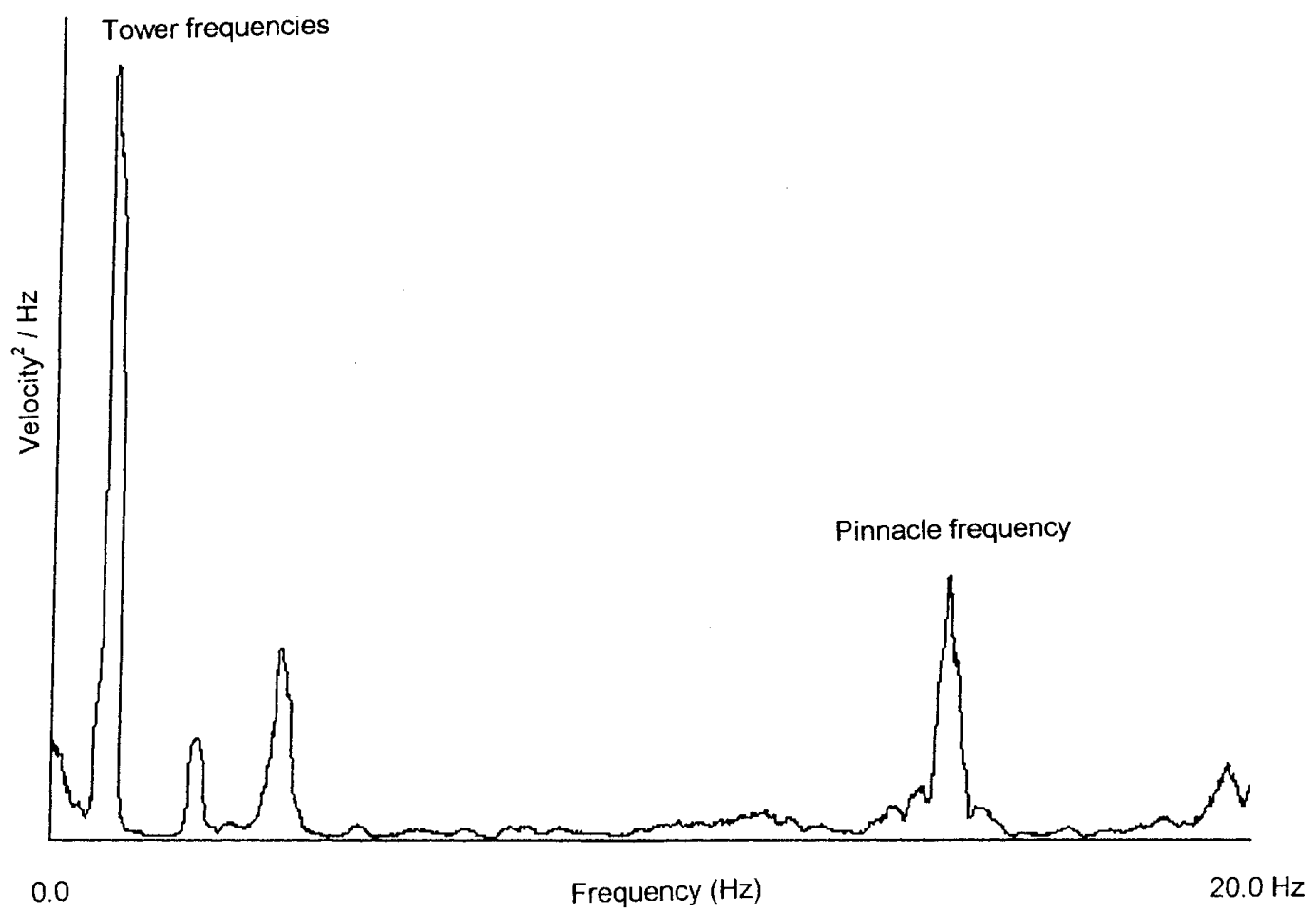

Fig. 4. Autospectrum measured for a pinnacle on the clock tower.

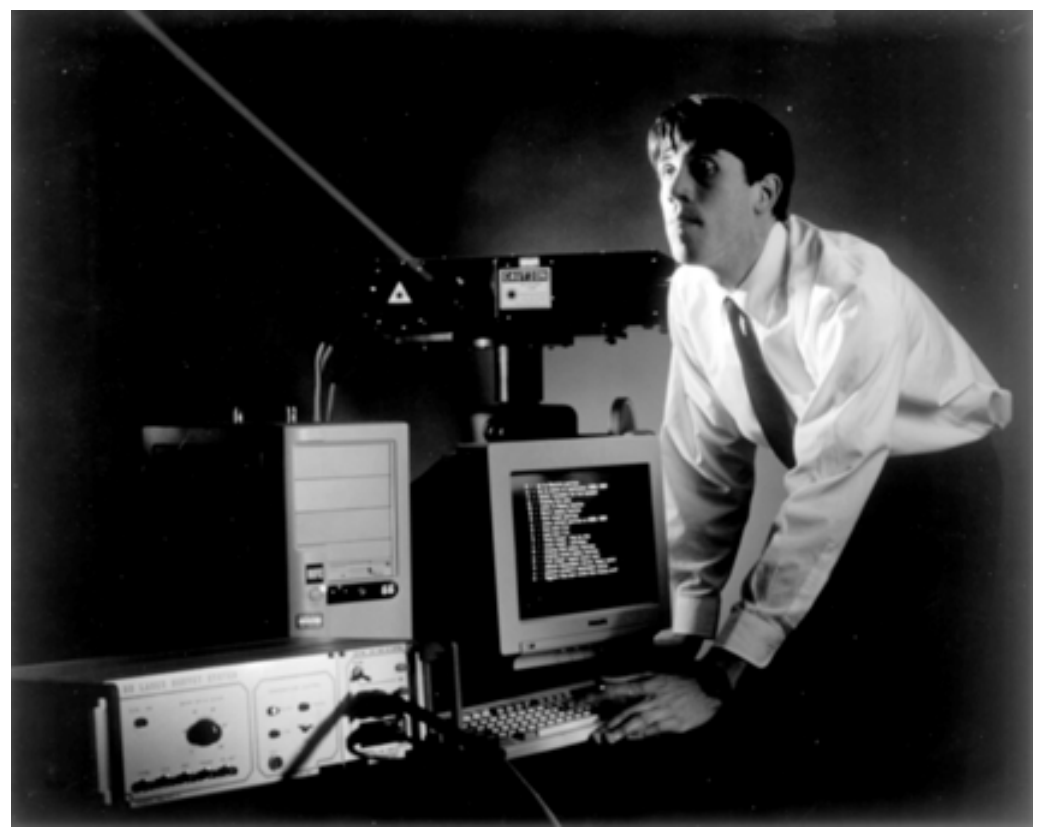

Fig. 5. The 3D-Laser Survey System in operation.

ment to an accuracy of $1 \mathrm{~mm}$ in three dimensions of retro-reflective targets attached to the building under investigation. Figure 5 shows the laser system which consists of a Laser Head Unit (L.H.U.), and an Electronics Control Unit (E.C.U.) controlled by a computer. The L.H.U. contains a temperature controlled Class II 


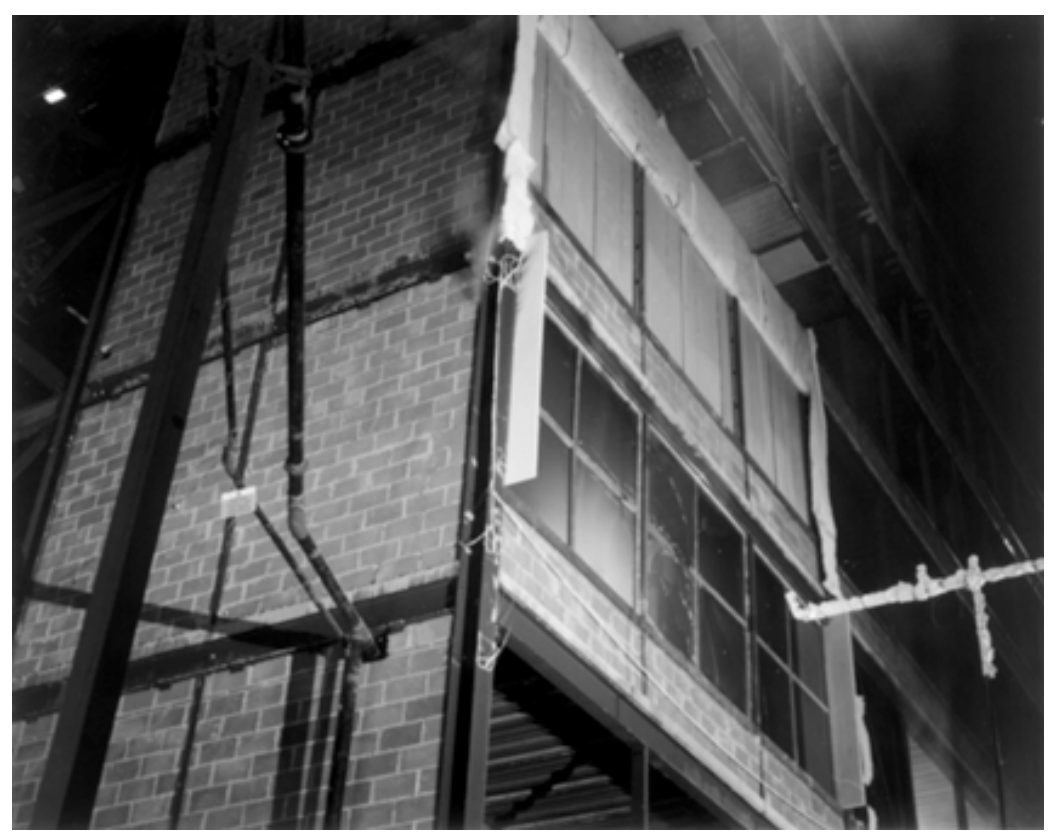

Fig. 6. Corner room fire test in steel building at Cardington.

laser with an output power of less than $1 \mathrm{~mW}$. Approximately $8 \%$ of the laser light is diverted via a prism into a U.H.F. reference unit to establish a reference signal. The remainder of the light is aimed at a target via two high-speed, electrically driven, precision steering mirrors. The mirrors move the laser through a total angle of $55.1^{\circ}$ in the horizontal plane in increments of $0.00532^{\circ}$, and through an angle of $53.0^{\circ}$ in the vertical plane in increments of $0.00508^{\circ}$. The target reflects the light into the Laser Head Unit where it is directed into the U.H.F. optical receiver board to establish a reflected signal. The U.H.F. reference and reflected signals are then sent to the E.C.U. where their phase difference is extracted in the Phase Detector Board. This phase difference can be equated to a change in range to the target, and with change in angular position measurements, the relative movement of a target can be determined in three dimensions.

The Electronics Control Unit also enables the user to control the beam spin diameter, for optimum beam size over the operating range of 3 to $30 \mathrm{~m}$. There is also electronic circuitry to control the temperature of the laser, to ensure that the laser tube remains the same length to produce laser light of the correct wavelength. Analogue to digital converters are then used to convert the output from the mirrors and phase measurement device to digital format for input into the computer. The computer contains software which can be used to direct the laser beam on to a target by controlling the two mirrors. When the laser beam is close to the target, a search routine can be started which spins the beam in ever increasing circles until the beam passes over the reflective target. During the search the computer will remember the position from which the strongest reflected signal was obtained and the target position is stored in the computer. The software can then be used to set up a routine to point the laser at each target in turn, and measure any change in target position during each survey. Up to 10 targets can be surveyed every 7 seconds, for an unlimited number of stored target positions, thus a complete survey takes longer when there are more targets to survey.

The 3D-LSS was initially developed to monitor the displacement of a blockwork wall during a full-scale fire test in the eight-storey, steel-framed building at the BRE's Cardington Laboratory. The fire test was set up in a second floor corner room, in a location where the use of traditional displacement instrument would be difficult because of the high temperatures and the room's height above the ground. A grid of 30 targets were placed on the external face of the blockwork wall and on the surrounding steel framework. Each target consisted of a $6 \mathrm{~mm}$ diameter disc of cheap reflective material attached to a plastic backing which was stuck to the wall with putty. The Laser Head Unit was set up on a heavy tripod at ground level, approximately ten metres from the base of the building. Each target position was stored in the computer and the sys- 


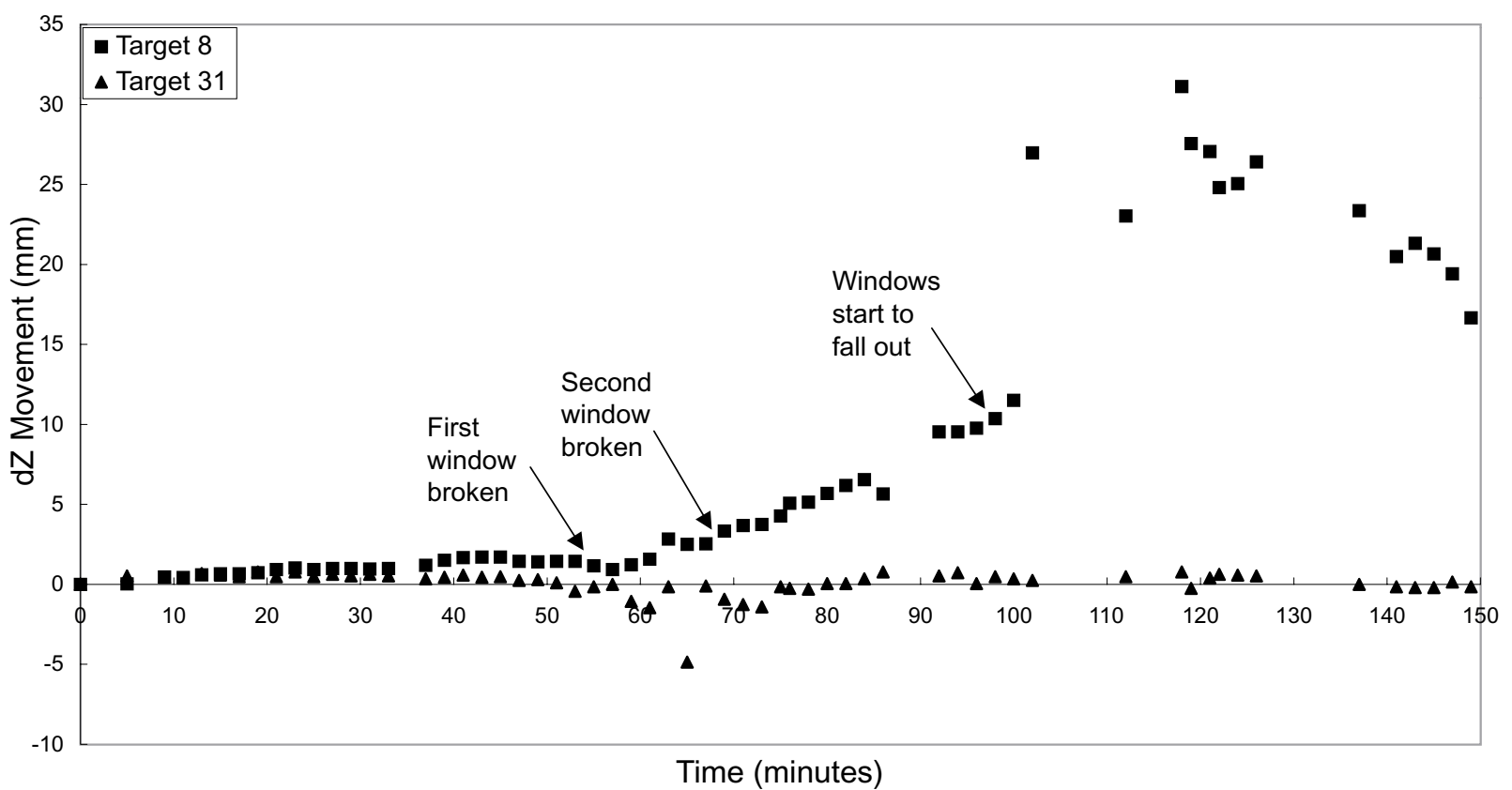

Fig. 7. Displacement-time plot of selected targets for the Cardington corner room fire test.

tem programmed to survey each target at two minute intervals.

Figure 6 shows the fire in the corner room, with one of the laser targets just visible one block to the left of the small yellow notice on the end blockwork wall. The fire was fuelled by twelve stacks of wooden tapers, ignited by burning paraffin soaked tapers. The room had double glazing windows along one side and a sealed door which unfortunately prevented oxygen from fuelling the fire during the first hour of the fire test. Figure 7 shows the movement with time of targets normal to the plane of the wall, where Target 8 is at the top of the wall and Target 31 is a control target remote from the fire. The wall moved about $1 \mathrm{~mm}$ as the fire smouldered for the first hour, until a window was broken to provide an increase in oxygen. The wall then moved rapidly outwards towards the laser head as the temperature increased inside the room. When all the windows fell out after 100 minutes, the wall moved to a maximum displacement of $31 \mathrm{~mm}$ from its initial position. As the temperature decreased, the graph shows the wall moving back towards its original position.

A comparison of room temperature with wall displacement shown in Fig. 8, reveals a close correlation between the two sets of data. The targets at the top of the wall moved the greatest amount where the heat was most intense whilst targets at the base of the wall moved very little. Interestingly, the targets at the mid-height of the wall moved into the room indicating that the wall was bowing rather than moving linearly outwards with respect to height above the wall base. Unfortunately, data from some of the targets at the top of the wall was lost when they melted in the heat or were covered by thick smoke. However in general, the use of the laser system was successful, providing displacement measurements which could not have been obtained with normal displacement transducers.

At present the 3D-LSS is best suited to the short term monitoring of structural displacement during loading tests carried out for research purposes. With modifications to the hardware such as a longer range laser and absolute distance measurement, the 3D-LSS would have many more potential uses in the fields of civil and structural engineering. These applications could include the short and long-term monitoring of movements of buildings, dams, tunnels and towers.

For instance, the 3D-LSS could be used for the longterm monitoring of walls and roofs of old historic buildings such as cathedrals, manor houses or castles. At present, structural engineers find it difficult to monitor long-term movement of ancient buildings suffering from sinking foundations, temperature effects and cracking. The 3D-LSS could be set up to measure the relative displacement of strategically placed targets and give warning of potentially dangerous movement. 


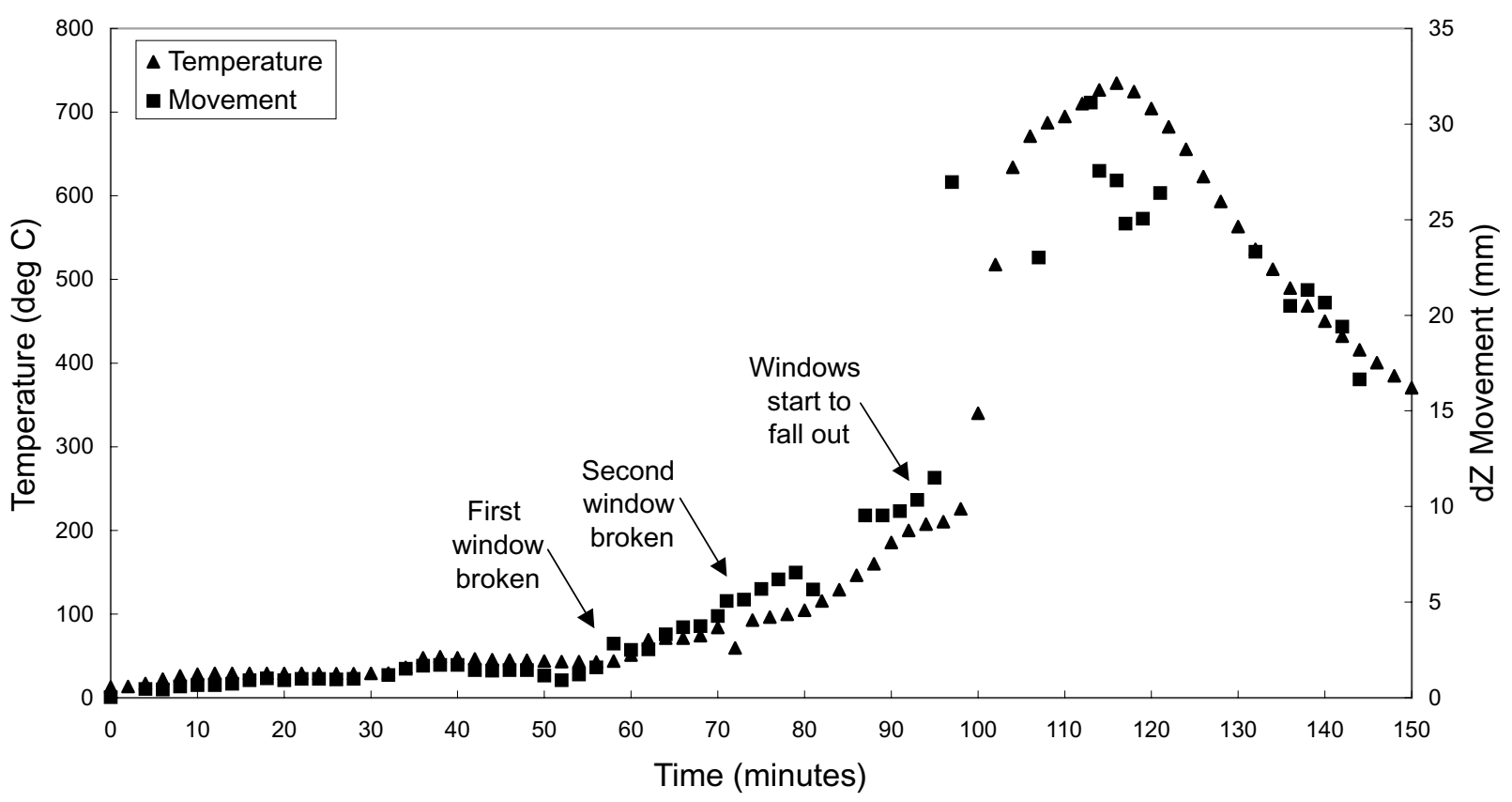

Fig. 8. Room temperature and wall displacement/ time plot for the Cardington corner room fire test.

\section{VHS Laser System}

The VHS Laser System can be used to measure the displacement of a single target at distances up to $100 \mathrm{~m}$ away. As the output signal can be sampled several thousand times a second, the VHS Laser is particularly suited to monitoring structural displacement under short duration impacts such as explosive forces or human impact loads. The system operates by sending a modulated beam of laser light to a reflective target attached to an object and measuring changes of phase of the reflected light due to the target moving or vibrating. This is achieved by comparing the returned modulation of the reflected light with the modulation of the outgoing light.

The operation of the VHS Laser is best illustrated by describing its use in measuring the displacement of concrete paving slabs subjected to releases of highly compressed air. The tests were carried out to investigate the strength and behaviour of materials under different rate of loading. Figure 9 shows the variable loading rate rig which consisted of two chambers connected by 49 holes in a steel valve plate which could be sealed by closing electro-magnetically controlled valves. With the valve plate sealed, the large chamber at the rear of the rig could be filled with compressed air to the desired pressure. When one or more of the valves is electrically opened, the compressed air is released into the small chamber to which the concrete slab had been bolted to at the front. By varying the number of valves opened, the rate of build up of air pressure on the back of the concrete slab can be changed to represent the effect of different types of explosion such as those fuelled by domestic gas or high explosives.

During the tests, the VHS Laser was set up on a heavy tripod placed to the side and in line with the front of the rig, so that the sudden release of compressed air and concrete fragments could not damage the equipment. The vertical and horizontal alignment controls on the tripod were used to direct the laser beam on to a mirror placed $2 \mathrm{~m}$ in front of the rig. By adjusting the angle and position of the mirror, the laser beam could be reflected to hit the centre of the concrete slab normally to ensure that displacement was not measured inaccurately on a skew. In other gas explosion tests at BRE's Cardington Laboratory, the laser travelled distances of approximately $20 \mathrm{~m}$ to a mirror and another $15 \mathrm{~m}$ to the test slab. When the laser beam was on the target, the focus control was adjusted to make the beam diameter the same size as the target. The tracking switch could then be turned on which enabled the laser to lock on to the target and follow its movement. The VHS laser measures $100 \mathrm{~mm}$ peak to peak of displacement in line with the laser beam with an output voltage signal of 0.2 Volts per mm of target displacement. The output voltage signal was recorded at sampling rates varying 


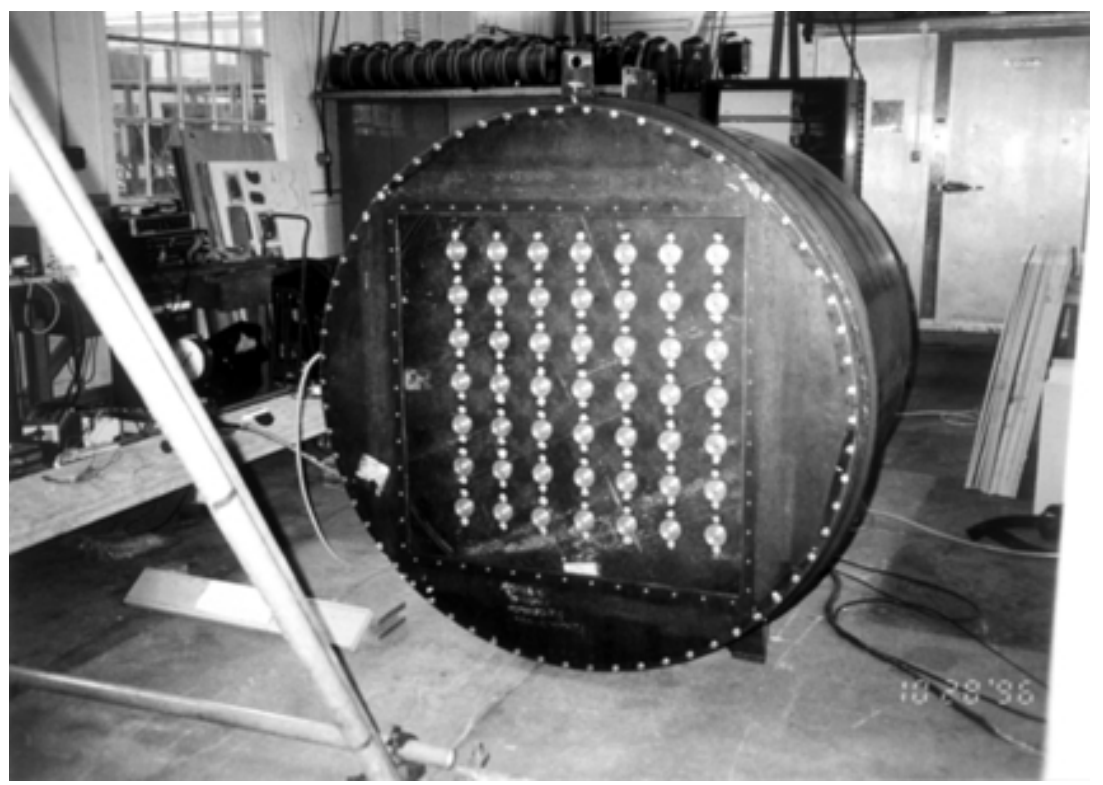

Fig. 9. Variable rate loading rig.

between $2000 \mathrm{~Hz}$ and $8000 \mathrm{~Hz}$ to monitor pressure releases that typically reached their peak within 100 milliseconds from when the valves were opened.

Figure 10 shows a typical plot of pressure and concrete slab displacement with time for a gas explosion test. The graph shows that as the pressure built up behind the concrete slab, the slab was pushed outwards, before breaking up after the pressure had remained at a peak for some $250 \mathrm{~ms}$. On one occasion the VHS Laser was calibrated against a displacement transducer placed adjacent to the laser target during one of the tests. The displacement-time graphs from the two systems were compared and found to be very similar in terms of amplitude and the shape of the graph, bearing in mind that the two sets of measurements could not be taken at exactly the same place. The displacement transducer was inevitably damaged by the failing panel.

Other work using the VHS Laser has included measuring the displacement of timber and steel barriers and stair treads subjected to human impact loads. These loads included pulling, pushing and leaning on the barrier, and jumping, running and walking on to stair treads. The laser beam was aimed directly or via a mirror on to reflective targets which were placed on the side of a barrier or beneath a stair tread. Displacement was then measured during the short duration impact loads imparted by a human volunteer. As a result of fast impact loads, the armatures in conventional displacement transducers can be pushed further than the actual structure moves giving an exaggerated displacement at the measurement position. The VHS Laser is a more accurate way of measuring the actual displacement of a structure for impact loads.

\section{Tracking lasers}

For tracking target movement in three dimensions a pair of tracking lasers is used. They track reflective targets in a similar way to the VHS Laser, but they do not measure the difference in phase of the reflected light to give a change in range measurement. Instead they give an output voltage proportional to the angular position of a target in the vertical and horizontal planes. By measuring the distance from the laser head to the target with a ruler or tape, it is an easy calculation to determine the actual distances moved by a target in the vertical and horizontal directions. However, the distance that the target moves along the line of the laser is not known, but can be determined if another laser is mounted orthogonally to track the same target.

The tracking lasers were first used to determine the quasi-static displacement of a building under wind loading and differential temperature effects. Several methods had been developed for calculating the response of tall buildings to wind loading but none of these had been calibrated against reliable data from real buildings. The building selected for the long term test, was a 23 storey unoccupied building called Hume Point close to the River Thames in East London [4]. The 


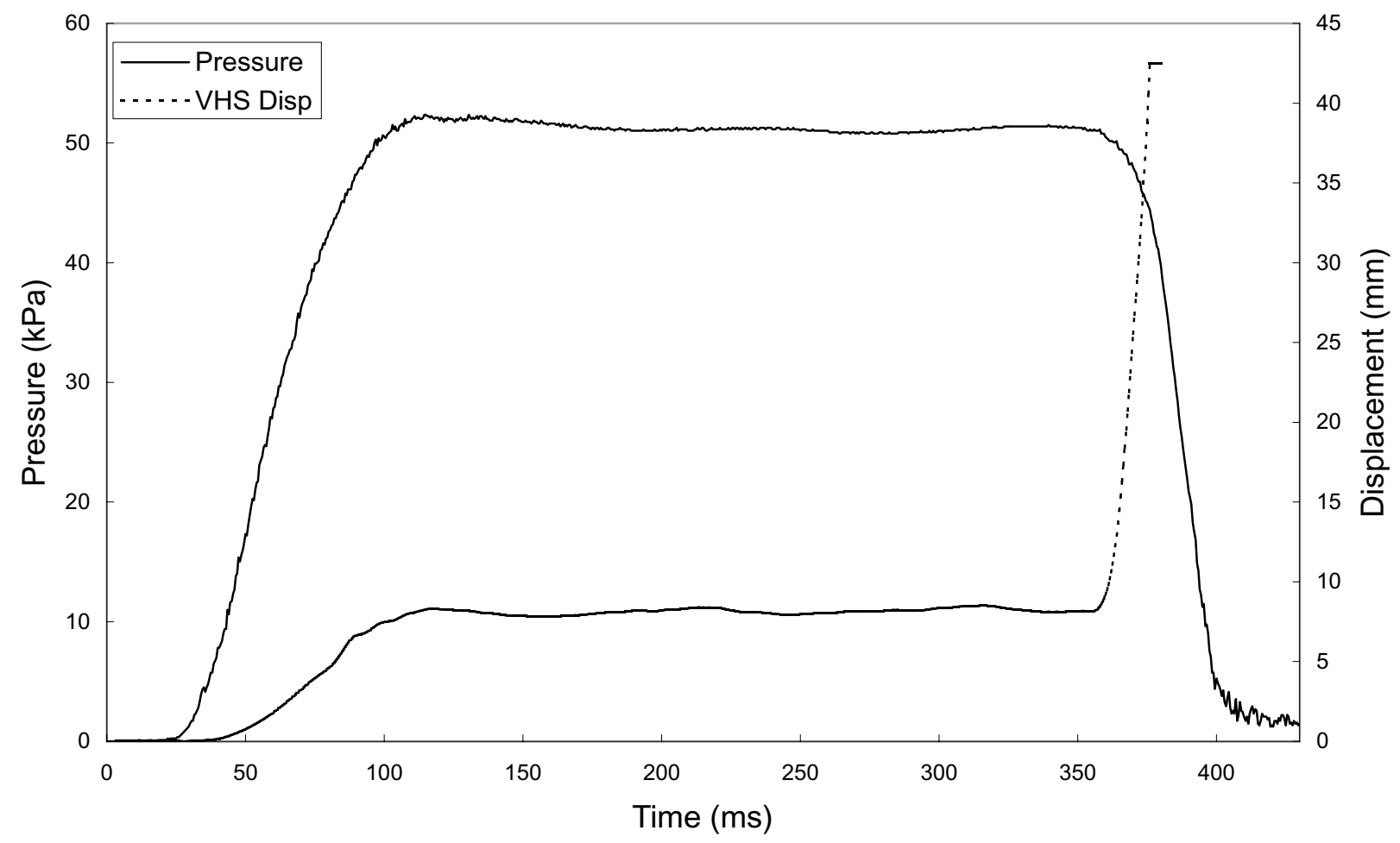

Fig. 10. Pressure and VHS laser displacement/ time histories for concrete paving slab.

building is a large precast concrete panel structure, with plan dimensions of $23.7 \mathrm{~m}$ by $17.9 \mathrm{~m}$ and a height of $66.9 \mathrm{~m}$.

Wind speed and direction were measured accurately by anemometers mounted on a $20 \mathrm{~m}$ mast above the roof of the building, whilst the dynamic response was measured by fourteen accelerometers placed over the building. The quasi-static response was measured by installing a plumb-line in one of the internal refuse chutes. This hung from the top of the building to the ground, with the mass at the base of the pendulum being immersed in oil to damp out high frequency vibrations. The pair of lasers on the second floor tracked the position of the plumb-line in two orthogonal directions, the output from them being used to determine the precise position of the plumb-line. Eight thermistors were also installed, two on each face, to establish how much of the quasi-static displacement of the plumb-line was due to differential temperature effects on the building. Thus the lean of the building under wind loading and temperature effects was accurately measured and could be compared to a calculated response derived from theoretical predictions.

One important consideration of this study was the effect of long-term drift on the output from the track- ing lasers. When electrical equipment is left turned on for months at a time, the variation in air temperature can affect the voltage output of the system. For this reason, the tracking lasers were programmed to selfcalibrate themselves every time they took a measurement of the plumb-line's position. This involved measuring the angular position of stationary targets either side of the plumb-line. As the angular position of the stationary targets should always be the same, any drift in the laser measurements could be subtracted from the measurements on the plumb-line.

The tracking lasers have also been used recently to measure the deflection in orthogonal directions of axially loaded struts. The tubular struts are used for propping scaffolding boards on construction sites. Figure 11 shows a strut in a loading machine with the tracking lasers positioned on either side. Each laser was aimed at a target placed on the east and south face of the prop and the laser was put in tracking mode. As the loading machine applied axial load to the prop, the lasers tracked the targets as the props bent under the load. With a manual measurement of the distance from the targets to the laser heads it was possible to plot loaddisplacement graphs for the prop in two orthogonal directions. 


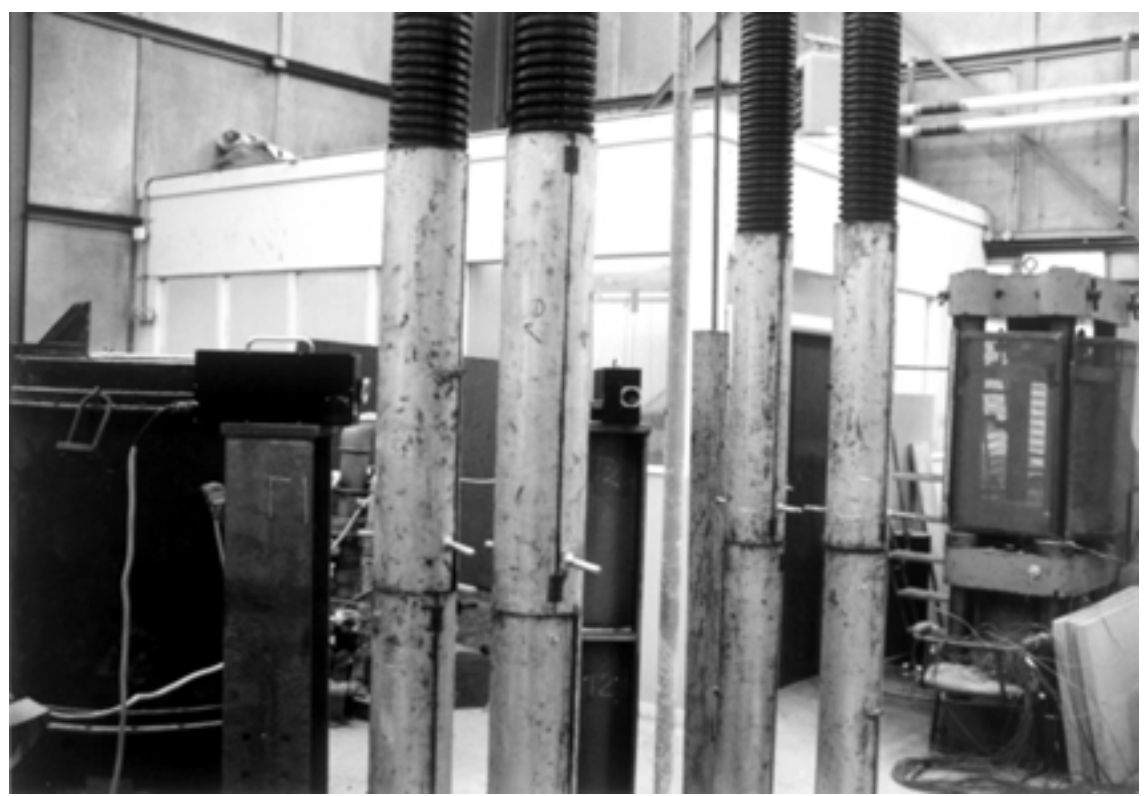

Fig. 11. Lasers tracking displacement of axially loaded scaffold pole (Photograph presented here with kind permission of the Health and Safety Executive).

\section{Concluding remarks}

In this paper, four different laser systems have been described, and their uses illustrated with examples of research work carried out by the BRE. Each laser system has its only particular use although some features are common to more than one system. All the laser systems allow measurements to be taken quickly and remotely with minimal interference to the structure or object under investigation. This is particular useful for taking measurements on large buildings where access is difficult and in hazardous environments where people and equipment can be damaged by fire, explosion or where there is a risk of structural collapse.

The laser interferometer can detect sub-micron vibration and can be used to measure the natural frequencies of buildings without the need to place targets or heavy equipment on the structure. This has opened up the possibility of being able to determine the dynamic behaviour of any building, bridge or tower in just a few hours work. Through an understanding of how stiffness is related to natural frequency, the laser interferometer makes it possible to remotely identify damage in cladding panels, roof pinnacles or other simple repeated structures.

The 3D-Laser Survey System can measure displacement in three dimensions to an accuracy of $1 \mathrm{~mm}$. An unlimited number of targets can be surveyed at a rate of one a second over ranges up to $30 \mathrm{~m}$. It is an invalu- able tool for short-term monitoring of structural displacement during loading tests for research purposes. With some modifications to the hardware, the laser system could periodically monitor displacement of both ancient and modern structures and provide an understanding of long-term behaviour.

The VHS Laser System is able to measure up to $100 \mathrm{~mm}$ of displacement of a target attached to a structure $100 \mathrm{~m}$ away. With an output that can be sampled up to 8000 times a second, the VHS Laser is particularly suited to monitoring displacement due to impacts of short duration. This includes explosive forces and human or vehicular impact on a structure.

Finally, the tracking lasers can measure angular position of a target just like the 3D-Laser Survey System, but has the advantage of being able to monitor from two different positions at the same time. The tracking lasers have been used in the laboratory and on site to monitor displacement in orthogonal directions without physical interference with the moving object.

\section{References}

[1] J. Uren and W.F. Price, Lasers in construction - the evolution continues, Civil Engineering, Proceedings of the Institution of Civil Engineers 120(1) (1997), 27-35.

[2] B.R. Ellis and T. Ji, Dynamic testing and numerical modelling of the Cardington steel framed building from construction to completion, The Structural Engineer 74(11) (1996), 186-192. 
[3] B.R. Ellis, Combined use of remote laser measurements and simple spectral analysis, NDT \& E International 30(4) (1997), 231-238.

[4] J.D. Littler and B.R. Ellis, Full-scale measurements to deter- mine the response of Hume Point to wind loading, Journal of Wind Engineering and Industrial Aerodynamics 41-44 (1992), 1085-1096. 

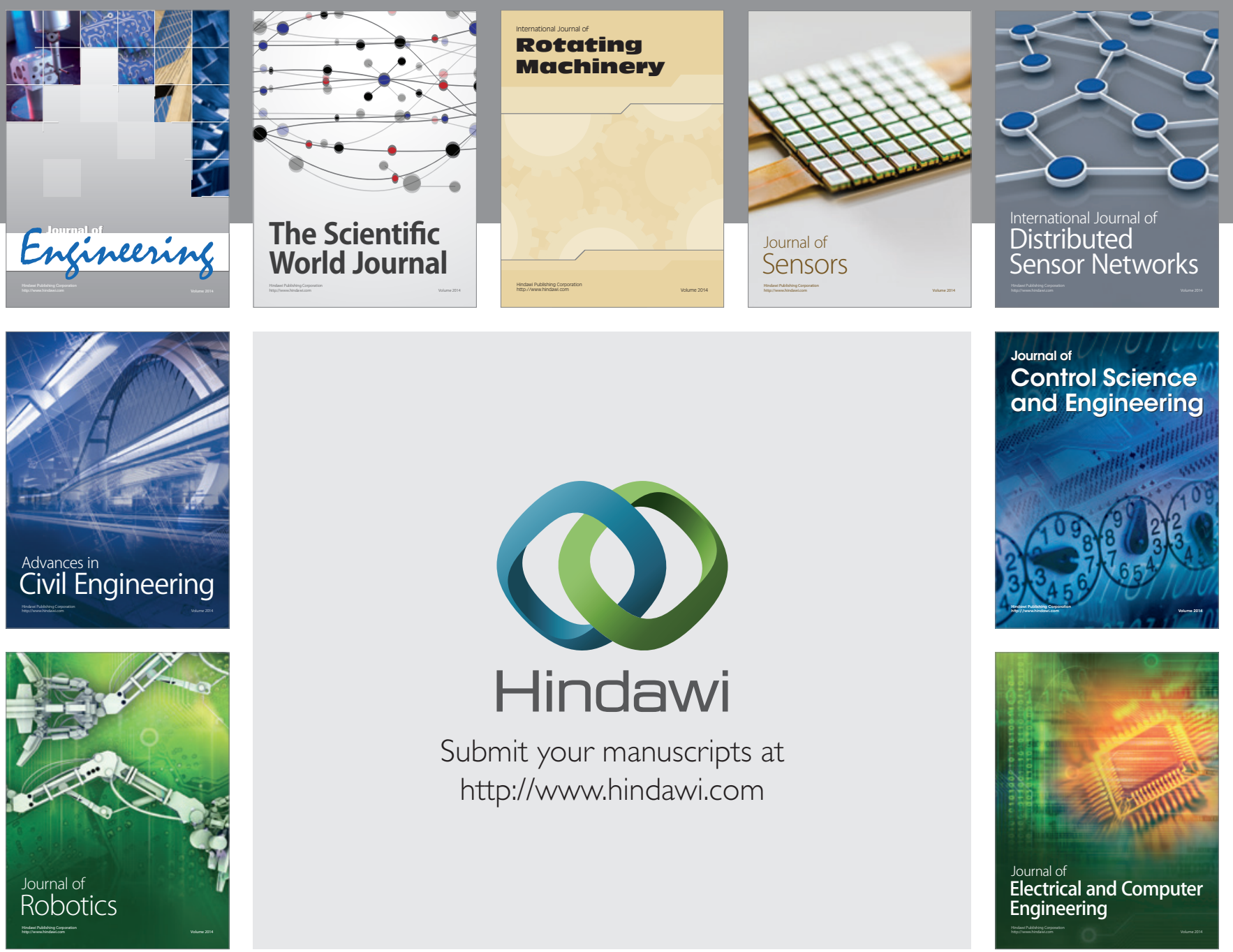

Submit your manuscripts at

http://www.hindawi.com
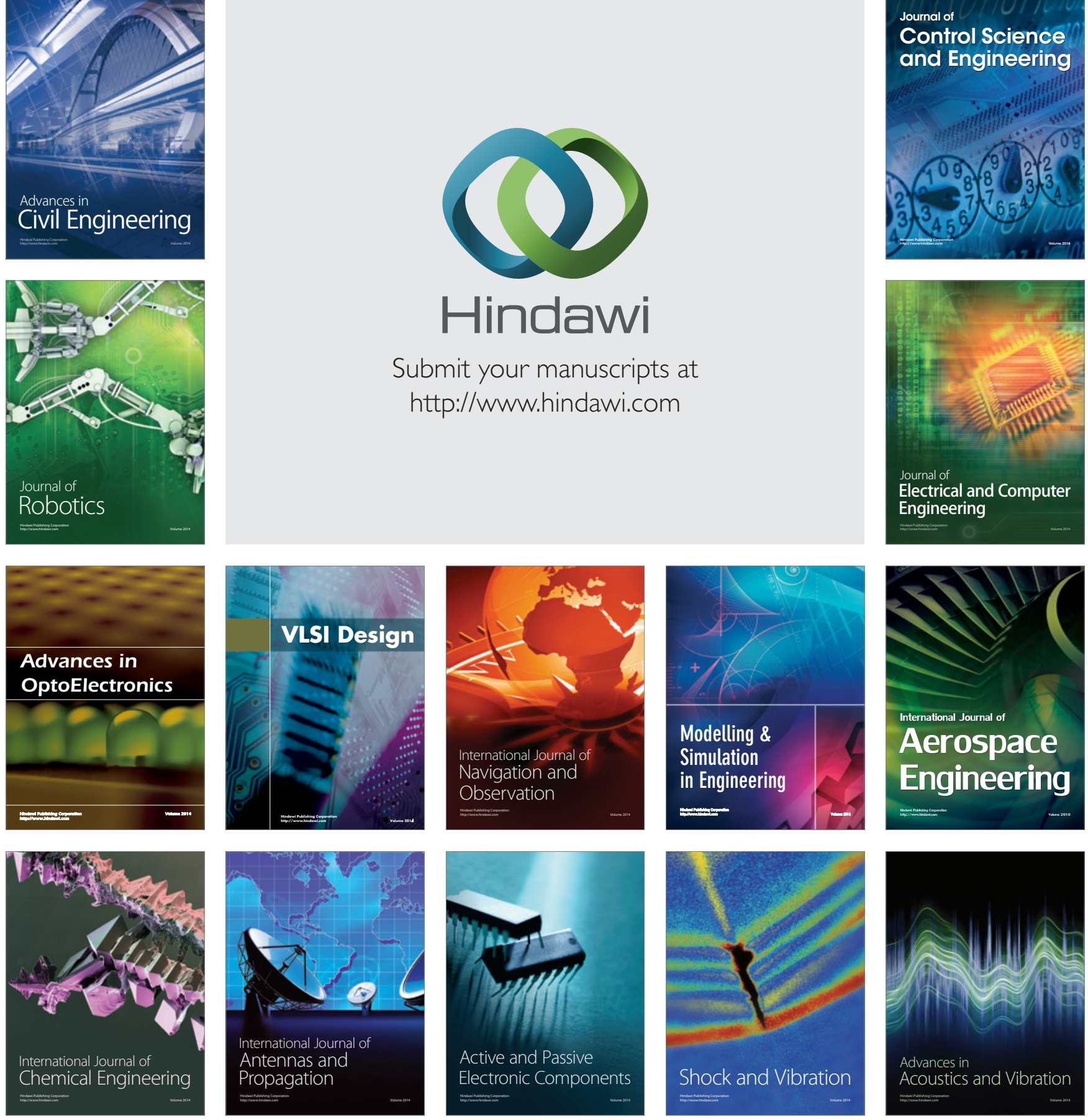